\title{
Diversidade arbórea das florestas alto montanas no Sul da Chapada Diamantina, Bahia, Brasil ${ }^{1}$
}

\author{
Francisco Haroldo Feitosa do Nascimento ${ }^{2,3}$, Ana Maria Giulietti² e Luciano Paganucci de Queiroz ${ }^{2}$
}

Recebido em 1/08/2009. Aceito em 17/05/2010

RESUMO - (Diversidade arbórea das florestas alto-montanas no Sul da Chapada Diamantina, Bahia, Brasil). A região do extremo Sul da Chapada Diamantina abriga as maiores altitudes do Nordeste brasileiro. Situam-se nessas serras as maiores elevações da região Nordeste, entre elas, o Pico do Barbado (2.033 m.s.n.m.). Dois dos rios mais importantes da Bahia nascem nestas serras: o Rio de Contas e o Rio Paramirim. A região é bem conhecida botanicamente, porém, este foi o primeiro inventário quantitativo realizado enfocando as formações florestais. Comparou-se a composição florística de 12 fragmentos de floresta montana, entre 1.350 e 1.750 m.s.n.m., tendo sido amostrados os indivíduos com PAP $\geq 8 \mathrm{~cm}$. Registrou-se a presença de 116 espécies em 84 gêneros de 48 famílias. As famílias com maior número de espécies foram Myrtaceae $(\mathrm{N}=20)$ e Lauraceae $(\mathrm{N}=10)$. Os gêneros com maior número de espécies foram Ocotea $(\mathrm{N}=7)$, Myrcia $(\mathrm{N}=5)$, Eugenia $(\mathrm{N}=4)$ e Miconia $(\mathrm{N}=4)$. A maioria das espécies apresentou padrão de distribuição amplo, mas foram encontradas espécies comuns a formações florestais de altitude do Sudeste e Sul do Brasil, como Drimys brasiliensis Miers (Winteraceae) e Weinmannia paulliniifolia Pohl (Cunnoniacae). A flora dos fragmentos estudados compartilha baixo número de espécies com as formações estacionais deciduais do entorno da Chapada Diamantina, indicando que estas florestas são únicas e merecem atenção especial, para sua conservação.

Palavras-chave: Diversidade arbórea, floresta alto-montana, Chapada Diamantina, fitogeografia

ABSTRACT - (Tree diversity of high montane forests in southern Chapada Diamantina, Bahia, Brazil). The southernmost region of Chapada Diamantina, nearest to Rio de Contas harbours the highest peaks of the Brazilian northeastern region, including Pico do Barbado (2,033 m.a.s.1.) and the source of the two important rivers in Bahia state (Rio de Contas and Rio Paramirim). The region is well known botanically. This was the first quantitative study to survey the floristic composition of 12 fragments of montane forests (1,350 m.a.s.l. to 1750 m.a.s.1.) including trees $\geq 8 \mathrm{cbh}$. A total of $117 \mathrm{species,} 84$ genera and 48 families were found. The richest families were Myrtaceae $(\mathrm{N}=20)$ and Lauraceae $(\mathrm{N}=10)$. The richest genera were Ocotea $(\mathrm{N}=7)$, Myrcia $(\mathrm{N}=5)$, Eugenia $(\mathrm{N}=4)$ and Miconia $(\mathrm{N}=4)$. Most species had wide geographic distributions, but some are found only in montane forests of southeastern and southern Brazil such as Drimys brasiliensis Miers (Winteraceae) and Weinmannia paulliniifolia Pohl (Cunnoniacae). The fragments studied have low similarity with seasonally dry tropical forests that surround Chapada Diamantina, emphasizing the uniqueness of these forests and the need for protection. Key words: tree diversity, high mountain forest, Chapada Diamantina, phytogeography

\section{Introdução}

De acordo com a Convenção da Diversidade Biológica (CDB), as montanhas são estruturalmente áreas que tendem a possuir as seguintes combinações físicas e biológicas: elevações altas e inclinadas, climas variados, grande composição de espécies nativas e endêmicas e diferentes graus de fragilidade. Funcionalmente, são as torres de água do mundo e podem servir de refúgio para muitas populações. Em suas terras baixas, as regiões montanhosas abrigam comunidades que dependem de suas provisões de bens e serviços, tais como água, energia, alimentação, madeira e recreação (Martinelli 2007).

As florestas que cobrem as montanhas são muito pouco estudadas e estão entre as mais ameaçadas de todas as vegetações florestais dos trópicos (Gentry 1995). Gentry (1982) e Myers et al. (2000) apontam que a necessidade de inventários é especialmente grande nos neotrópicos, que apresentam seis centros de biodiversidade (hotspots) e cerca de $35 \%$ das espécies de angiospermas do mundo.

No Brasil, as florestas de altitude ou montanas ocorrem no alto dos planaltos ou serras e têm sido subdivididas em montanas e alto-montanas, dependendo das faixas de altitude e das latitudes (Veloso et al. 1991). Oliveira-Filho et al. (2006), através de análises multivariadas de dados florísti- cos e classificando a vegetação de acordo com a formação vegetacional, a altitude e a região geográfica, definem que, para latitudes $<16^{\circ} \mathrm{S}$, as formações de terras baixas ocupariam a faixa até os 400 m.s.n.m.; altitudes entre 400 e 800 m seriam classificadas como sub-montanas; as formações baixo montanas seriam aquelas que se situam entre os $800 \mathrm{e}$ $1200 \mathrm{~m}$, enquanto que formações acima dos 1200 m.s.n.m. seriam consideradas como alto-montanas.

No Nordeste, as florestas ombrófilas alto montanas ocorrem nas serras isoladas e disjuntas da porção Sul da Chapada Diamantina. Sob a denominação de florestas altomontanas, podem ser incluídas as florestas de encosta, florestas nebulares e as florestas de grotão (Harley \& Simmons 1986; Harley 1995; Giulietti et al. 1996). Associadas a estas florestas, nascem grande parte dos rios da Bahia. Existem, nestas serras, algumas áreas de preservação, destacando-se o Parque Nacional da Chapada Diamantina, na porção central, e a APA do Barbado, mais ao Sul.

As florestas montanas de Pernambuco, Ceará e Paraíba têm sido estudadas desde a década de 1940 (Oliveira \& Andrade-Lima 1948; Andrade 1954; Andrade-Lima 1953). $\mathrm{Na}$ Bahia, os primeiros estudos realizados nestas florestas datam do final da década de 1990, quando algumas abordagens florísticas, para as florestas serranas, começaram

\footnotetext{
Parte da Tese de Doutorado do primeiro Autor

2 Universidade Estadual de Feira de Santana, Programa de Pós-graduação em Botânica, Feira de Santana, BA, Brasil

Autor para correspondência: franciscoharoldof@gmail.com
} 
a dar uma idéia de sua composição (Funch et al. 2005). Funch (1997) concluiu que as florestas baixo-montanas do município de Lençóis (BA) são constituídas por espécies que apresentam distribuição geográfica ampla, podendo a região ser considerada como um local de afluxo de diferentes floras. Este foi o primeiro estudo quantitativo, com a flora arbórea, efetuado na Chapada Diamantina.

Apesar dos esforços realizados para a elaboração da flora do Pico das Almas (Stannard 1995) e da flora de Catolés (Zappi et al. 2003), onde foi encontrado grande número de novas espécies e também de espécies endêmicas, não foram tomados dados da vegetação florestal.

As florestas da porção Sul da Chapada Diamantina estão sofrendo acelerada degradação, o que remonta à história das lavras diamantinas e auríferas (Harley 1995), associada ao uso intensivo do fogo para abrir pasto para o gado, à procura de madeira para construção, até a expansão de áreas agrícolas nos momentos atuais (Funch et al. 2005).

O presente trabalho visa aumentar o conhecimento sobre a composição florística das florestas alto-montanas da Chapada Diamantina, investigar as relações fitogeográficas desta flora com outras formações florestais brasileiras e gerar subsídios para a conservação e manutenção deste importante patrimônio biológico e paisagístico.

\section{Material e métodos}

Área de Estudo - A área de estudo abrange os municípios de Rio de Contas e Rio do Pires. Ambos localizam-se na porção centro-sul do estado da Bahia. A sede administrativa de Rio de Contas localiza-se às coordenadas de $13^{\circ} 35^{\prime}$ de latitude sul e $41^{\circ} 48^{\prime}$ de longitude oeste e a sede administrativa do município de Rio do Pires, às coordenadas $13^{\circ} 09^{\prime} \mathrm{S}$ e $41^{\circ} 46^{\prime} \mathrm{W}$. O clima é mesotérmico brando, tipo Cwb (Köppen 1936), caracterizado como tropical semi-úmido, com verão chuvoso e inverno seco. As chuvas têm um máximo no verão (novembro, dezembro e janeiro) e um pico secundário em março-abril; de agosto a novembro as chuvas diminuem, formando a estação seca (Harley 1995). Na Chapada Diamantina, as médias anuais são inferiores a $22^{\circ} \mathrm{C}$, com temperaturas mais baixas no inverno.

O relevo é montanhoso, acidentado, com vales encaixados e elevações que ultrapassam 1800 m.s.n.m. Nessa região encontra-se o ponto culminante do Nordeste, o Pico do Barbado, com 2.033 m.s.n.m. Nos maciços e serras altas, os solos são em geral rasos, pedregosos e pobres, predominando os Neossolos Litólicos (rasos, pedregosos e de fertilidade baixa) e grandes afloramentos de rocha. Nos topos planos, os solos são em geral mais profundos e muito pobres, com predominância de Latossolos profundos, bem drenados, ácidos e de fertilidade baixa (Nolasco et al. 2005).

A lista florística aqui apresentada foi obtida por meio do levantamento fitossociológico de 12 fragmentos situados na porção sul da Chapada Diamantina, Bahia (Tab. 1). Foram amostrados seis fragmentos na Serra das Almas (Parque Municipal de Rio de Contas; $13^{\circ} 31^{\prime} \mathrm{S}, 41^{\circ} 58^{\prime} \mathrm{W}$ ), cinco na Serra da Mesa (Pico do Itoibira, APA Serra do Barbado; $13^{\circ} 22^{\prime} \mathrm{S}, 41^{\circ} 53^{\prime} \mathrm{W}$ ), município de Rio de Contas, e um na Serra Itubira (Mata do Cigano, APA Serra do Barbado; $\left.13^{\circ} 15^{\prime} \mathrm{S}, 41^{\circ} 55^{\prime} \mathrm{W}\right)$, município de Rio do Pires. Nestas localidades, são encontradas as maiores elevações do Nordeste. Dois dos mais importantes rios da Bahia nascem nessas serras, o rio de Contas, que deságua no oceano Atlântico, e o rio Paramirim, maior afluente da margem direita do rio São Francisco, no estado da Bahia. São áreas montanhosas de difícil acesso e as florestas encontradas na região são, em sua maioria, florestas de grotão, florestas de encosta e florestas ciliares, estando ligadas à presença da água. Todos os fragmentos situam-se acima dos 1.350 m.s.n.m. São comuns chuvas orográficas, assim como é constante a neblina, que contribuem para o aumento da disponibilidade hídrica. Tais condições de umidade permitem a presença de populações de epífitas e briófitas.
Foram amostrados apenas fragmentos que possuíam paisagem tipicamente florestal, independentemente do estádio sucessional e do histórico de uso, sendo amostrados os indivíduos com PAP $\geq 8 \mathrm{~cm}$. Foram coletados os indivíduos que apresentavam botões, flores e frutos, nas parcelas e na vegetação do entorno. Foram coletados indivíduos férteis de todas as espécies amostradas no levantamento fitossociológico. As coletas foram geo-referenciadas, processadas segundo as técnicas usuais de herborização (Mori et al. 1989) e os espécimes foram depositados no Herbário de Universidade Estadual de Feira de Santana (HUEFS). A identificação do material foi feita por meio de literatura especializada, comparação com o material depositado no HUEFS e, na maioria dos casos, por especialistas. A confirmação dos nomes e dos autores foi feita através dos sites http://mobot. mobot.org/W3T/Search/vast.html, do Missouri Botanical Garden e http:// www.ipni.org/, do The International Plant Name Index. A classificação taxonômica segue APG II (2003). Para análise dos padrões fitogeográficos, foram obtidos dados de distribuição de espécies através de revisões taxonômicas e de bancos informatizados dos herbários HUEFS, MO, NY e RB.

\section{Resultados}

Florística dos fragmentos - Foram encontradas 116 espécies em 84 gêneros e 47 famílias (Tab. 2). As famílias com maior número de espécies foram Myrtaceae (20 espécies), Lauraceae (10), Melastomataceae (6), Asteraceae (5), Leguminosae (4), Rubiaceae (4) e Vochysiaceae (4), representando cerca de $45 \%$ do total. Cinco famílias apresentaram três espécies, 13 famílias duas espécies e 22 famílias apresentaram apenas uma espécie. Desta forma, cerca de $85 \%$ das famílias (40) incluem $55 \%$ das espécies (63).

Os gêneros com maior número de espécies foram Ocotea (7 espécies), Myrcia (5), Eugenia (4), Miconia (4), Marlierea (3), Pouteria (3) e Vochysia (3). Juntos, estes gêneros correspondem a cerca de $25 \%$ do número total de espécies. Onze gêneros apresentaram duas espécies, enquanto que 68 apresentaram uma única espécie, ou seja, cerca de 92\% dos gêneros (79) respondem por cerca de $75 \%$ do número de espécies amostradas (87 espécies).

Das 116 espécies, 15 são arbustos ou sub-arbustos, que no interior da mata alcançaram o critério de inclusão, e uma é palmeira. Nove destas são características do sub-bosque, podendo ser citadas Inga lenticellata, Leandra melastomoides e Piper cernuum. Cinco são encontradas na vegetação campestre adjacente e eventualmente colonizam clareiras ou áreas antropizadas no interior dos fragmentos, exemplos são Senna cana e Eriope macrostachya. Geonoma brevispatha ocorre em áreas úmidas no interior da mata, principalmente à beira de cursos d'água.

Noventa espécies foram encontradas nos seis fragmentos localizados na Serra das Almas (Tab. 2). Nos cinco fragmentos estudados na Serra da Mesa, foram registradas 73 espécies. No fragmento localizado na Serra do Barbado (Mata do Cigano) foram coletadas 51 espécies. Onze espécies são comuns aos 12 fragmentos, são elas: Guatteria sellowiana, Alchornea triplinervia, Ocotea daphnifolia e O. spixiana, Miconia caudigera e M. rimalis, Macropeplus ligustrinus, Myrsine umbellata, Myrcia guianensis Psidium rufum e Siphoneugena dussii, sendo que todas possuem síndrome de dispersão zoocórica. 
Tabela 1. Quadro comparativo dos parâmetros gerais dos doze fragmentos amostrados no extremo sul da Chapada Diamantina, municípios de Rio de Contas ( $13^{\circ} 35^{\prime}$

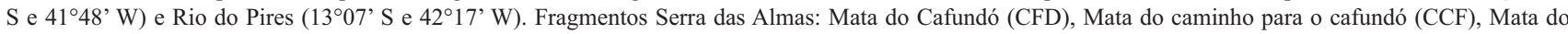
Chiquinho (CHQ), Mata do caminho para o Pico das Almas (CPA), Mata do Gambá (GMB) e Gaia da Mata (GAI). Fragmentos Serra da Mesa: Mata do Cabecinha (CBC), Mata da Campina Estreita (CMP), Mata da Subida (SUB), Fragmento Osório (OSR) e Fragmento Silvano (SVN). Mata do Cigano (CIG). As coordenadas referem-se a pontos centrais nos fragmentos.

\begin{tabular}{|c|c|c|c|c|c|c|c|c|c|c|c|c|}
\hline \multirow[b]{2}{*}{ Parâmetros/Fragmentos } & \multicolumn{6}{|c|}{ Serra das Almas } & \multicolumn{5}{|c|}{ Serra da Mesa } & \multirow{2}{*}{$\frac{\text { Cigano }}{\text { CIG }}$} \\
\hline & CFD & $\mathrm{CCF}$ & CHQ & CPA & GMB & GAI & $\mathrm{CBC}$ & CMP & SUB & OSR & SVN & \\
\hline Latitude (S) & $13^{\circ} 30^{\prime} 43^{\prime \prime}$ & $13^{\circ} 31^{\prime} 43^{\prime \prime}$ & $13^{\circ} 31^{\prime} 58^{\prime \prime}$ & $13^{\circ} 31^{\prime} 26^{\prime \prime}$ & $13^{\circ} 31^{\prime} 27^{\prime \prime}$ & $13^{\circ} 32^{\prime} 18^{\prime \prime}$ & $13^{\circ} 21^{\prime} 55^{\prime \prime}$ & $13^{\circ} 21^{\prime} 56^{\prime \prime}$ & $13^{\circ} 22^{\prime} 27^{\prime \prime}$ & $13^{\circ} 22^{\prime} 14^{\prime \prime}$ & $13^{\circ} 22^{\prime} 08^{\prime \prime}$ & $13^{\circ} 15^{\prime} 50^{\prime \prime}$ \\
\hline Longitude (W) & $41^{\circ} 57^{\prime} 45^{\prime \prime}$ & $41^{\circ} 57^{\prime} 16^{\prime \prime}$ & $41^{\circ} 56^{\prime} 11^{\prime \prime}$ & $41^{\circ} 57^{\prime} 18^{\prime \prime}$ & $41^{\circ} 56^{\prime} 43^{\prime \prime}$ & $41^{\circ} 54^{\prime} 14^{\prime \prime}$ & $41^{\circ} 53^{\prime} 16^{\prime \prime}$ & $41^{\circ} 53^{\prime} 07^{\prime \prime}$ & $41^{\circ} 52^{\prime} 51^{\prime \prime}$ & $41^{\circ} 53^{\prime} 19^{\prime \prime}$ & $41^{\circ} 53^{\prime} 24^{\prime \prime}$ & $41^{\circ} 55^{\prime} 04^{\prime \prime}$ \\
\hline Altitude (m.s.n.m.) & 1550 & 1500 & 1400 & 1500 & 1500 & 1350 & 1650 & 1600 & 1650 & 1600 & 1600 & 1750 \\
\hline Área fragmento (ha.) & 5,4 & 0,9 & 10 & 1,9 & 3 & 2,2 & 7,5 & 10,6 & 9,5 & 6,6 & 3,8 & 31 \\
\hline Perímetro fragmento $(\mathrm{km})$ & 1 & 0,4 & 3,6 & 0,6 & 0,8 & 0,6 & 1,5 & 2 & 1,3 & 1,2 & 1 & 3,2 \\
\hline $\mathrm{N}^{0}$ de espécies (S) & 52 & 41 & 47 & 48 & 37 & 62 & 45 & 53 & 49 & 45 & 44 & 51 \\
\hline $\mathrm{N}^{\mathrm{o}}$ famílias & 23 & 21 & 24 & 21 & 20 & 32 & 26 & 29 & 26 & 25 & 24 & 31 \\
\hline
\end{tabular}

Os indivíduos de Guatteria sellowiana, Ocotea spixiana, Myrsine umbellata, Myrcia guianensis, Psidium rufum e Alchornea triplinervia apesar de serem grandes árvores no interior das matas desenvolvem também nanoformas (ou ecotipos sensu Clausen, Keck \& Hiesey apud Baldwin 2006) que habitam entre as rochas dos campos rupestres circunvizinhos. As espécies precedentes somados a Miconia caudigera e Siphoneugena dussii são geralmente plantas componentes do dossel. Destacando-se os indivíduos de Miconia caudigera que são essencialmente florestais e podem atingir 18 metros de altura. Ocotea daphnifolia e Macropeplus ligustrinus são conspícuas formadoras do subosque, enquanto os indivíduos de Miconia rimalis são importantes formadores do subdossel. Trinta e sete espécies são exclusivas dos fragmentos localizados na Serra das Almas, oito são encontradas apenas nos fragmentos da Serra da Mesa e quatro na Mata do Cigano (Tab. 2).

$\mathrm{O}$ fragmento com maior número de espécies foi Gaia da Mata (GAI; Serra das Almas; 62 espécies) e o fragmento com o menor número de espécies foi Mata do Gambá (GMB; Serra das Almas; 37) (Tab. 1).

Vinte e duas espécies (cerca de 20\%) ocorrem em apenas um dos doze fragmentos. Aspidosperma discolor, Eremanthus incanus, Ocotea percoriacea e O. pomaderroides, Inga lenticellata, Senna cana, Ficus citrifolia, Psidium salutare, Heisteria perianthomega, Pouteria andarahiensis, Aureliana brasiliana, Symplocos lanceolata e Qualea cryptantha ocorrem em apenas um dos fragmentos da Serra das Almas. Schefflera sp. nov. ined., Hedyosmum brasiliense, Clusia melchiori, Weinmannia paulliniifolia e Solanum cladotrichum ocorrem em apenas um dos fragmentos da Serra da Mesa. Euterpe edulis, Verbesina luetzelburguii, Sloanea monosperma e Myrcia blanchetiana ocorrem apenas na Mata do Cigano. Algumas destas espécies são importantes na estruturação da comunidade e emprestam características únicas para a composição da paisagem, como por exemplo, Sloanea monosperma, que é emergente do dossel na Mata do Cigano. Outras indicam a existência de condições cli- máticas mais amenas, por serem comumente encontradas em florestas montanas, como Hedyosmum brasiliense e Weinmannia paulliniifolia.

Padrão de distribuição geográfica das espécies - A grande maioria das espécies que ocorrem nas áreas estudadas (55) apresenta distribuição geográfica ampla, podendo ter um padrão contínuo ou disjunto. Os limites dessa distribuição geralmente atingem o Trópico de Capricórnio ao Sul e, ao Norte, os limites do Brasil ou da América do Sul. Apesar da maioria das espécies apresentarem padrão de distribuição amplo, estas podem ser incluídas em cinco padrões principais (Tab. 2).

A) Padrão Neotropical: podem ser incluídas neste padrão 31 espécies, das quais 13 apresentam-se restritas a América do Sul. Apresentam distribuição mais ou menos contínua e ocorrem em diferentes tipos de florestas, como as ciliares, amazônicas, restingas e semi-deciduais.

B) Disjunto entre o Norte da América do Sul e o leste do Brasil: são 23 espécies que ocorrem geralmente nas áreas florestais montanhosas das Guianas e Venezuela ou nos Andes.

C) Periamazônico: São oito espécies com distribuição nos estados do nordeste, centro-oeste e sudeste, até São Paulo.

D) Endêmico da Cadeia do Espinhaço: São 17 espécies que apresentam seu centro de diversidade na Cadeia do Espinhaço, apesar de poderem apresentar populações fora da área core. Dessas, seis ocorrem disjuntamente nas florestas de Minas Gerais e Bahia, como por exemplo, Myrcia mischophylla e Solanum cladotrichum, quatro são disjuntas com a mata atlântica como Ocotea percoriacea e sete são endêmicas das montanhas da Chapada Diamantina, são elas: Ocotea sp. nov. ined., Schefflera sp. nov. ined., $P a$ ralychnophora harleyi, Verbesina luetzelburguii, Faramea nigrescens, Pouteria andarahiensis e Byrsonima stannardii.

E) Restrito ao Leste e Centro-Oeste Brasileiros: São 37 espécies com centro de diversidade na floresta Atlântica. Dessas, 24 ocorrem nos estados do nordeste e sudeste, mas 
Tabela 2. Espécies encontradas nos fragmentos amostrados no extremo sul da Chapada Diamantina, municípios de Rio de Contas ( $\left(13^{\circ} 35^{\prime} \mathrm{S}\right.$ e $41^{\circ} 48^{\prime}$ W) e Rio do Pires (130. $7^{\prime} \mathrm{S}$ e $\left.42^{\circ} 17^{\prime} \mathrm{W}\right)$. Fragmentos Serra das Almas: Gaia da Mata (Gai), Mata do Gambá (Gmb), Mata do caminho para o Pico das Almas (Cpa), Mata do Chiquinho (Chq), Mata do caminho para o cafundó (Ccf) e Mata do Cafundó (Cfd). Fragmentos Serra da Mesa: Mata da Campina Estreita (Cmp), Mata da Subida (Sub), Fragmento Silvano (Svn), Mata do Cabecinha (Cbc) e Fragmento Osório (Osr). Serra Itubira (SI): Mata do Cigano (Cig). Padrões de distribuição geográfica (PDG): A) Neotropical; B) Disjunto entre o Norte da América do Sul e o Leste do Brasil; C) Periamazônico; D) Endêmico da Cadeia do Espinhaço; e E) Leste e Centro-Oeste do Brasil. Estratos florestais: Subosque (SB); Subdossel (SD); Dossel (D); Emergentes (EM).

\begin{tabular}{llllllllllllllll}
\hline & \multicolumn{4}{c}{ Serra das Almas } & \multicolumn{4}{c}{ Serra da Mesa } \\
\hline Famílias/Espécies & PDG & Gai & Gmb & Cpa & Chq & Cef & Cfd & Cmp & Sub & Svn & Cbc & Osr & Cig \\
\hline
\end{tabular}

ANACARDIACEAE

Tapirira obtusa (Benth.) J.D. Mitch.

SB

ANNONACEAE

Annona cacans Warm.

Guatteria sellowiana Schltdl.

APOCYNACEAE

Aspidosperma discolor A. DC.

Aspidosperma nobile Müll. Arg.

Hancornia speciosa B.A. Gomes

AQUIFOLIACEAE

Ilex psammophila Reissek

Ilex theezans Mart.

ARALIACEAE

Schefflera aff. calva (Cham.) Frodin \& Fiaschi

Schefflera sp. nov. ined.

ARECACEAE

Euterpe edulis Mart.

Geonoma brevispatha Barb. Rodr.

ASTERACEAE

Baccharis brachylaenoides DC.

Eremanthus glomerulatus Less.

Eremanthus incanus (Less.) Less.

Paralychnophora harleyi (H. Rob.) D.J.N. Hind

Verbesina luetzelburguii Mattf.

BIGNONIACEAE

Handroanthus ochraceus (Cham.) Mattos.

CELASTRACEAE

Maytenus gonoclada Mart.

Plenckia populnea Reissek

CHLORANTHACEAE

Hedyosmum brasiliense Miq.

CLETHRACEAE

Clethra scabra Pers.

CLUSIACEAE

Clusia criuva Cambess.

Clusia melchiori Gleason

Garcinia brasiliensis Mart.

DS

DS

DS

DS

SB

SD

DS

DS

DS

DS

SB

DS

DS

SD

SD

DS

DS

SB

B

A

$A$

E

S

D

D

S E

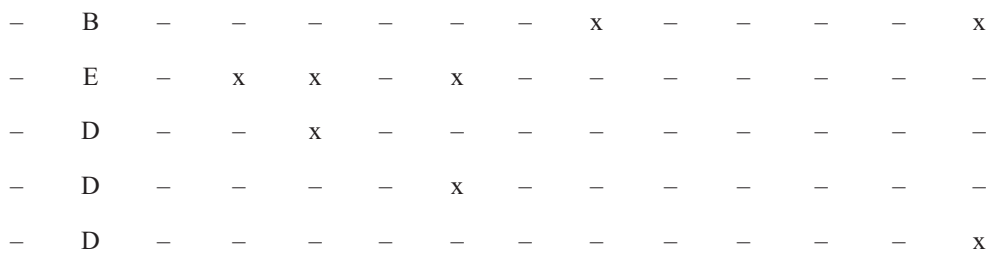

B $x$

DS 
Tabela 2. Continuação.

\begin{tabular}{|c|c|c|c|c|c|c|c|c|c|c|c|c|c|c|}
\hline \multirow{2}{*}{ Famílias/Espécies } & & & \multicolumn{6}{|c|}{ Serra das Almas } & \multicolumn{4}{|c|}{ Serra da Mesa } & \multicolumn{2}{|r|}{ SI } \\
\hline & & PDG & Gai & $\mathrm{Gmb}$ & Cpa & Chq & $\mathrm{Ccf}$ & $\mathrm{Cfd}$ & $\mathrm{Cmp}$ & Sub & Svn & $\mathrm{Cbc}$ & Osr & Cig \\
\hline \multicolumn{15}{|l|}{ CUNNONIACEAE } \\
\hline Lamanonia ternata Vell. & DS & A & $\mathrm{x}$ & $\mathrm{x}$ & $\mathrm{x}$ & $\mathrm{x}$ & - & $\mathrm{x}$ & $\mathrm{x}$ & - & $\mathrm{x}$ & - & $\mathrm{x}$ & $\mathrm{x}$ \\
\hline Weinmannia paulliniifolia Pohl & DS & $\mathrm{B}$ & - & - & - & - & - & - & - & $\mathrm{x}$ & - & - & - & - \\
\hline \multicolumn{15}{|l|}{ ELAEOCARPACEAE } \\
\hline Sloanea monosperma Vell. & EM & A & - & - & - & - & - & - & - & - & - & - & - & $\mathrm{x}$ \\
\hline \multicolumn{15}{|l|}{ EUPHORBIACEAE } \\
\hline Alchornea triplinervia (Spreng.) Müll. Arg. & DS & A & $\mathrm{x}$ & $\mathrm{x}$ & $\mathrm{x}$ & $\mathrm{x}$ & $\mathrm{x}$ & $\mathrm{x}$ & $\mathrm{x}$ & $\mathrm{x}$ & $\mathrm{x}$ & $\mathrm{x}$ & $\mathrm{x}$ & $\mathrm{x}$ \\
\hline Pera glabrata (Schott) Poepp. ex Baill. & $\mathrm{SD}$ & A & - & - & $\mathrm{x}$ & - & - & $\mathrm{x}$ & - & - & - & - & - & - \\
\hline Sapium glandulatum (Vell.) Pax & SB & A & $\mathrm{x}$ & - & - & - & - & - & - & - & $\mathrm{x}$ & - & - & - \\
\hline \multicolumn{15}{|l|}{ HUMIRIACEAE } \\
\hline Vantanea compacta (Schnizl.) Cuatrec. & DS & A & - & $\mathrm{x}$ & - & $\mathrm{x}$ & - & - & - & - & - & - & - & - \\
\hline \multicolumn{15}{|l|}{ LAMIACEAE } \\
\hline Eriope macrostachya Mart. ex Benth. & SB & $\mathrm{B}$ & $\mathrm{x}$ & - & - & - & - & $\mathrm{x}$ & - & - & - & - & - & - \\
\hline \multicolumn{15}{|l|}{ LAURACEAE } \\
\hline Cinnamomum glaziovii (Mez) Kosterm. & DS & $\mathrm{E}$ & $\mathrm{x}$ & - & $\mathrm{x}$ & - & - & $\mathrm{x}$ & $\mathrm{x}$ & $\mathrm{x}$ & $\mathrm{x}$ & $\mathrm{x}$ & $\mathrm{x}$ & - \\
\hline Cinnamomum haussknechtii (Mez) Kosterm. & DS & $\mathrm{E}$ & - & $\mathrm{x}$ & - & - & $\mathrm{x}$ & - & - & - & $\mathrm{x}$ & - & - & - \\
\hline Ocotea aciphylla (Nees) Mez & DS & A & $\mathrm{x}$ & $\mathrm{x}$ & $\mathrm{x}$ & $\mathrm{x}$ & - & $\mathrm{x}$ & $\mathrm{x}$ & $\mathrm{x}$ & $\mathrm{x}$ & $\mathrm{x}$ & $\mathrm{x}$ & $\mathrm{x}$ \\
\hline Ocotea daphnifolia (Meisn.) Mez & SB & $\mathrm{E}$ & $\mathrm{x}$ & $\mathrm{x}$ & $\mathrm{x}$ & $\mathrm{x}$ & $\mathrm{x}$ & $\mathrm{x}$ & $\mathrm{x}$ & $\mathrm{x}$ & $\mathrm{x}$ & $\mathrm{x}$ & $\mathrm{x}$ & $\mathrm{x}$ \\
\hline Ocotea glaziovii Mez & DS & $\mathrm{E}$ & - & - & - & - & - & - & $\mathrm{x}$ & $\mathrm{x}$ & $\mathrm{x}$ & $\mathrm{x}$ & $\mathrm{x}$ & $\mathrm{x}$ \\
\hline Ocotea percoriacea (Meisn.) Kosterm. & SB & $\mathrm{D}$ & - & - & $\mathrm{x}$ & - & - & - & - & - & - & - & - & - \\
\hline Ocotea pomaderroides (Meisn.) Mez & DS & $\mathrm{E}$ & - & - & $\mathrm{x}$ & - & - & - & - & - & - & - & - & - \\
\hline Ocotea spixiana (Nees) $\mathrm{Mez}$ & DS & $\mathrm{E}$ & $\mathrm{x}$ & $\mathrm{x}$ & $\mathrm{x}$ & $\mathrm{x}$ & $\mathrm{x}$ & $\mathrm{x}$ & $\mathrm{x}$ & $\mathrm{x}$ & $\mathrm{x}$ & $\mathrm{x}$ & $\mathrm{x}$ & $\mathrm{x}$ \\
\hline Ocotea sp. nov. ined. & DS & $\mathrm{D}$ & $\mathrm{x}$ & - & - & - & - & - & $\mathrm{x}$ & $\mathrm{x}$ & $\mathrm{x}$ & $\mathrm{x}$ & $\mathrm{x}$ & $\mathrm{x}$ \\
\hline Persea major (Nees) L.E. Kopp & DS & $\mathrm{E}$ & $\mathrm{x}$ & - & $\mathrm{x}$ & - & $\mathrm{x}$ & $\mathrm{x}$ & $\mathrm{x}$ & $\mathrm{x}$ & $\mathrm{x}$ & $\mathrm{x}$ & - & $\mathrm{x}$ \\
\hline \multicolumn{15}{|l|}{ LEGUMINOSAE } \\
\hline Ormosia fastigiata Tul. & DS & A & - & - & - & - & - & - & $\mathrm{x}$ & $\mathrm{x}$ & $\mathrm{x}$ & $\mathrm{x}$ & $\mathrm{x}$ & - \\
\hline Inga lenticellata Benth. & SB & $\mathrm{E}$ & $\mathrm{x}$ & - & - & - & - & - & - & - & - & - & - & - \\
\hline Tachigali rugosa (Mart. ex Benth.) Zarucchi \& Pipoly & EM & $\mathrm{B}$ & $\mathrm{x}$ & - & $\mathrm{x}$ & $\mathrm{x}$ & $\mathrm{x}$ & - & - & - & - & - & - & - \\
\hline Senna cana (Nees \& C. Mart.) H. S. Irwin \& Barneby & SB & $\mathrm{E}$ & - & - & $\mathrm{x}$ & - & - & - & - & - & - & - & - & - \\
\hline \multicolumn{15}{|l|}{ MALPHIGIACEAE } \\
\hline Byrsonima stannardii W.R. Anderson & DS & $\mathrm{D}$ & $\mathrm{x}$ & $\mathrm{x}$ & $\mathrm{x}$ & $\mathrm{x}$ & $\mathrm{x}$ & $\mathrm{x}$ & $\mathrm{x}$ & - & $\mathrm{x}$ & $\mathrm{x}$ & $\mathrm{x}$ & $\mathrm{x}$ \\
\hline \multicolumn{15}{|l|}{ MELASTOMATACEAE } \\
\hline Leandra melastomoides Raddi & SB & $\mathrm{E}$ & $\mathrm{x}$ & - & - & $\mathrm{x}$ & - & $\mathrm{x}$ & $\mathrm{x}$ & $\mathrm{x}$ & - & $\mathrm{x}$ & - & $\mathrm{x}$ \\
\hline Miconia caudigera DC. & DS & $\mathrm{E}$ & $\mathrm{x}$ & $\mathrm{x}$ & $\mathrm{x}$ & $\mathrm{x}$ & $\mathrm{x}$ & $\mathrm{x}$ & $\mathrm{x}$ & $\mathrm{x}$ & $\mathrm{x}$ & $\mathrm{x}$ & $\mathrm{x}$ & $\mathrm{x}$ \\
\hline Miconia chartacea Triana & SB & $\mathrm{E}$ & $\mathrm{x}$ & $\mathrm{x}$ & $\mathrm{x}$ & - & - & $\mathrm{x}$ & $\mathrm{x}$ & $\mathrm{x}$ & - & $\mathrm{x}$ & $\mathrm{x}$ & - \\
\hline Miconia pepericarpa Mart. ex DC. & SB & $\mathrm{E}$ & - & $\mathrm{x}$ & $\mathrm{x}$ & $\mathrm{x}$ & $\mathrm{x}$ & $\mathrm{x}$ & - & - & - & - & - & - \\
\hline Miconia rimalis Naudin & $\mathrm{SD}$ & $\mathrm{D}$ & $\mathrm{x}$ & $\mathrm{x}$ & $\mathrm{x}$ & $\mathrm{x}$ & $\mathrm{x}$ & $\mathrm{x}$ & $\mathrm{x}$ & $\mathrm{x}$ & $\mathrm{x}$ & $\mathrm{x}$ & $\mathrm{x}$ & $\mathrm{x}$ \\
\hline Tibouchina fissinervia Cogn. & DS & $\mathrm{E}$ & - & - & $\mathrm{x}$ & - & - & - & $\mathrm{x}$ & - & - & $\mathrm{x}$ & - & - \\
\hline \multicolumn{15}{|l|}{ MELIACEAE } \\
\hline Cabralea canjerana (Vell.) Mart. & EM & $\mathrm{B}$ & $\mathrm{x}$ & $\mathrm{x}$ & - & - & - & $\mathrm{x}$ & $\mathrm{x}$ & $\mathrm{x}$ & $\mathrm{x}$ & $\mathrm{x}$ & $\mathrm{x}$ & - \\
\hline \multicolumn{15}{|l|}{ MONIMIACEAE } \\
\hline Macropeplus ligustrinus (Tul.) Perkins & SB & $\mathrm{E}$ & $\mathrm{x}$ & $\mathrm{x}$ & $\mathrm{x}$ & $\mathrm{x}$ & $\mathrm{x}$ & $\mathrm{x}$ & $\mathrm{x}$ & $\mathrm{x}$ & $\mathrm{x}$ & $\mathrm{x}$ & $\mathrm{x}$ & $\mathrm{x}$ \\
\hline \multicolumn{15}{|l|}{ MORACEAE } \\
\hline Ficus bahiensis C.C. Berg \& Carauta & DS & $\mathrm{E}$ & $\mathrm{x}$ & - & - & $\mathrm{x}$ & - & - & - & - & - & - & $\mathrm{x}$ & $\mathrm{x}$ \\
\hline Ficus citrifolia Mill. & DS & A & $\mathrm{x}$ & - & - & - & - & - & - & - & - & - & - & - \\
\hline
\end{tabular}


Tabela 2. Continuação.

\begin{tabular}{|c|c|c|c|c|c|c|c|c|c|c|c|c|c|c|}
\hline \multirow[b]{2}{*}{ Famílias/Espécies } & & & \multicolumn{6}{|c|}{ Serra das Almas } & \multicolumn{4}{|c|}{ Serra da Mesa } & \multicolumn{2}{|r|}{ SI } \\
\hline & & PDG & Gai & $\mathrm{Gmb}$ & Cpa & Chq & $\mathrm{Ccf}$ & Cfd & $\mathrm{Cmp}$ & Sub & Svn & $\mathrm{Cbc}$ & Osr & Cig \\
\hline \multicolumn{15}{|l|}{ MYRSINACEAE } \\
\hline Myrsine guianensis (Aubl.) Kuntze & SB & $\mathrm{B}$ & $\mathrm{x}$ & - & $\mathrm{x}$ & - & - & - & - & - & - & - & - & - \\
\hline Myrsine umbellata Mart. & DS & $\mathrm{B}$ & $\mathrm{x}$ & $\mathrm{x}$ & $\mathrm{x}$ & $\mathrm{x}$ & $\mathrm{x}$ & $\mathrm{x}$ & $\mathrm{x}$ & $\mathrm{x}$ & $\mathrm{x}$ & $\mathrm{x}$ & $\mathrm{x}$ & $\mathrm{x}$ \\
\hline \multicolumn{15}{|l|}{ MYRTACEAE } \\
\hline Blepharocalyx salicifolius (Kunth) O. Berg & EM & $\mathrm{C}$ & $\mathrm{x}$ & - & $\mathrm{x}$ & $\mathrm{x}$ & $\mathrm{x}$ & $\mathrm{x}$ & $\mathrm{x}$ & - & $\mathrm{x}$ & $\mathrm{x}$ & $\mathrm{x}$ & - \\
\hline Calyptranthes pulchella DC. & DS & $\mathrm{B}$ & $\mathrm{x}$ & $\mathrm{x}$ & $\mathrm{x}$ & $\mathrm{x}$ & $\mathrm{x}$ & $\mathrm{x}$ & $\mathrm{x}$ & - & $\mathrm{x}$ & - & $\mathrm{x}$ & $\mathrm{x}$ \\
\hline Eugenia cerasiflora Miq. (Figena) & DS & $\mathrm{E}$ & $\mathrm{x}$ & $\mathrm{x}$ & $\mathrm{x}$ & $\mathrm{x}$ & $\mathrm{x}$ & $\mathrm{x}$ & $\mathrm{x}$ & $\mathrm{x}$ & $\mathrm{x}$ & $\mathrm{x}$ & $\mathrm{x}$ & - \\
\hline Eugenia ligustrina (Sw.) Willd. & DS & $\mathrm{B}$ & - & - & - & - & - & - & - & $\mathrm{x}$ & $\mathrm{x}$ & $\mathrm{x}$ & $\mathrm{x}$ & $\mathrm{x}$ \\
\hline Eugenia punicifolia (Kunth) DC. & $\mathrm{SD}$ & A & $\mathrm{x}$ & $\mathrm{x}$ & $\mathrm{x}$ & $\mathrm{x}$ & $\mathrm{x}$ & $\mathrm{x}$ & - & - & - & - & - & - \\
\hline Eugenia rostrata DC. & DS & $\mathrm{E}$ & - & - & - & - & - & - & $\mathrm{x}$ & $\mathrm{x}$ & $\mathrm{x}$ & $\mathrm{x}$ & $\mathrm{x}$ & $\mathrm{x}$ \\
\hline Gomidesia lindeniana $\mathrm{O}$. Berg & $\mathrm{SD}$ & $\mathrm{B}$ & $\mathrm{x}$ & $\mathrm{x}$ & $\mathrm{x}$ & $\mathrm{x}$ & - & $\mathrm{x}$ & $\mathrm{x}$ & $\mathrm{x}$ & $\mathrm{x}$ & $\mathrm{x}$ & $\mathrm{x}$ & $\mathrm{x}$ \\
\hline Marlierea laevigata (DC.) Kiaersk. & DS & $\mathrm{D}$ & $\mathrm{x}$ & $\mathrm{x}$ & $\mathrm{x}$ & $\mathrm{x}$ & $\mathrm{x}$ & $\mathrm{x}$ & $\mathrm{x}$ & - & - & - & - & - \\
\hline Marlierea pilodes (Kiaersk.) Kawasaki & DS & $\mathrm{D}$ & - & $\mathrm{x}$ & $\mathrm{x}$ & $\mathrm{x}$ & $\mathrm{x}$ & $\mathrm{x}$ & - & - & - & - & - & - \\
\hline Marlierea warmingiana Kiersk. & DS & $\mathrm{E}$ & $\mathrm{x}$ & - & - & - & - & $\mathrm{x}$ & - & - & - & - & - & - \\
\hline Myrceugenia alpigena (DC.) Landrum & $\mathrm{SD}$ & $\mathrm{E}$ & - & - & - & - & - & $\mathrm{x}$ & $\mathrm{x}$ & - & - & - & - & $\mathrm{x}$ \\
\hline Myrcia blanchetiana $\mathrm{O}$. Berg & SB & $\mathrm{E}$ & - & - & - & - & - & - & - & - & - & - & - & $\mathrm{x}$ \\
\hline Myrcia fallax (Rich.) DC. & $\mathrm{SD}$ & A & $\mathrm{x}$ & - & $\mathrm{x}$ & $\mathrm{x}$ & $\mathrm{x}$ & $\mathrm{x}$ & - & - & - & - & - & - \\
\hline Myrcia guianensis (Aubl.) DC. & DS & A & $\mathrm{x}$ & $\mathrm{x}$ & $\mathrm{x}$ & $\mathrm{x}$ & $\mathrm{x}$ & $\mathrm{x}$ & $\mathrm{x}$ & $\mathrm{x}$ & $\mathrm{x}$ & $\mathrm{x}$ & $\mathrm{x}$ & $\mathrm{x}$ \\
\hline Myrcia mischophylla Kiaersk. & SD & $\mathrm{D}$ & - & $\mathrm{x}$ & $\mathrm{x}$ & $\mathrm{x}$ & $\mathrm{x}$ & - & - & - & - & - & - & - \\
\hline Myrcia venulosa DC. & SB & $\mathrm{E}$ & - & - & $\mathrm{x}$ & - & $\mathrm{x}$ & $\mathrm{x}$ & $\mathrm{x}$ & $\mathrm{x}$ & $\mathrm{x}$ & - & $\mathrm{x}$ & - \\
\hline Pimenta pseudocaryophyllus (Gomes) Landrum & SB & A & $\mathrm{x}$ & - & - & - & $\mathrm{x}$ & - & - & - & - & - & - & - \\
\hline Psidium rufum DC. & DS & $\mathrm{E}$ & $\mathrm{x}$ & $\mathrm{x}$ & $\mathrm{x}$ & $\mathrm{x}$ & $\mathrm{x}$ & $\mathrm{x}$ & $\mathrm{x}$ & $\mathrm{x}$ & $\mathrm{x}$ & $\mathrm{x}$ & $\mathrm{x}$ & $\mathrm{x}$ \\
\hline Psidium salutare (Kunth) O. Berg & SB & $\mathrm{B}$ & - & - & - & - & - & $\mathrm{x}$ & - & - & - & - & - & - \\
\hline Siphoneugena dussii (Krug \& Urb.) Proença & DS & A & $\mathrm{x}$ & $\mathrm{x}$ & $\mathrm{x}$ & $\mathrm{x}$ & $\mathrm{x}$ & $\mathrm{x}$ & $\mathrm{x}$ & $\mathrm{x}$ & $\mathrm{x}$ & $\mathrm{x}$ & $\mathrm{x}$ & $\mathrm{x}$ \\
\hline \multicolumn{15}{|l|}{ NYCTAGINACEAE } \\
\hline Guapira opposita (Vell.) Reitz & DS & $\mathrm{B}$ & $\mathrm{x}$ & - & - & - & - & $\mathrm{x}$ & - & - & - & - & - & $\mathrm{x}$ \\
\hline \multicolumn{15}{|l|}{ OLACACEAE } \\
\hline Heisteria perianthomega (Vell.) Sleumer & SB & $\mathrm{E}$ & $\mathrm{x}$ & - & - & - & - & - & - & - & - & - & - & - \\
\hline \multicolumn{15}{|l|}{ OLEACEAE } \\
\hline Chionanthus crassifolius (Mart.) P.S. Green & SB & $\mathrm{E}$ & - & - & $\mathrm{x}$ & - & - & $\mathrm{x}$ & - & - & - & - & - & - \\
\hline \multicolumn{15}{|l|}{ PHYLLANTHACEAE } \\
\hline Hieronyma alchorneoides Allemão & DS & $\mathrm{B}$ & - & - & - & - & - & $\mathrm{x}$ & - & $\mathrm{x}$ & - & - & - & - \\
\hline \multicolumn{15}{|l|}{ PIPERACEAE } \\
\hline Piper cernuum Vell. & SB & A & - & - & - & - & - & - & - & $\mathrm{x}$ & - & $\mathrm{x}$ & - & - \\
\hline Piper lhotzkyanum Kunth & SB & A & $\mathrm{x}$ & - & - & $\mathrm{x}$ & - & - & $\mathrm{x}$ & $\mathrm{x}$ & - & $\mathrm{x}$ & - & - \\
\hline \multicolumn{15}{|l|}{ PODOCARPACEAE } \\
\hline Podocarpus lambertii Klotzsch ex Endl. & DS & $\mathrm{E}$ & - & - & - & - & - & - & - & $\mathrm{x}$ & - & - & - & $\mathrm{x}$ \\
\hline \multicolumn{15}{|l|}{ PROTEACEAE } \\
\hline Euplassa legalis (Vell.) I.M. Johnst. & DS & $\mathrm{D}$ & $\mathrm{x}$ & $\mathrm{x}$ & $\mathrm{x}$ & $\mathrm{x}$ & - & $\mathrm{x}$ & $\mathrm{x}$ & $\mathrm{x}$ & $\mathrm{x}$ & $\mathrm{x}$ & $\mathrm{x}$ & $\mathrm{x}$ \\
\hline Roupala rhombifolia Mart. ex Meisn. & DS & $\mathrm{B}$ & $\mathrm{x}$ & $\mathrm{x}$ & $\mathrm{x}$ & $\mathrm{x}$ & $\mathrm{x}$ & $\mathrm{x}$ & $\mathrm{x}$ & $\mathrm{x}$ & $\mathrm{x}$ & - & $\mathrm{x}$ & $\mathrm{x}$ \\
\hline \multicolumn{15}{|l|}{ RHAMNACEAE } \\
\hline Rhamnus sphaerosperma Sw. & DS & $\mathrm{B}$ & - & - & - & - & - & - & - & - & - & $\mathrm{x}$ & $\mathrm{x}$ & - \\
\hline \multicolumn{15}{|l|}{ ROSACEAE } \\
\hline Prunus myrtifolia Koehne & $\mathrm{SD}$ & A & $\mathrm{x}$ & - & - & $\mathrm{x}$ & $\mathrm{x}$ & - & $\mathrm{x}$ & - & $\mathrm{x}$ & $\mathrm{x}$ & $\mathrm{x}$ & $\mathrm{x}$ \\
\hline
\end{tabular}


Tabela 2. Continuação.

\begin{tabular}{|c|c|c|c|c|c|c|c|c|c|c|c|c|c|c|}
\hline \multirow{2}{*}{ Famílias/Espécies } & & & \multicolumn{6}{|c|}{ Serra das Almas } & \multicolumn{5}{|c|}{ Serra da Mesa } & \multirow{2}{*}{$\frac{\text { SI }}{\text { Cig }}$} \\
\hline & & PDG & Gai & $\mathrm{Gmb}$ & Cpa & Chq & Ccf & Cfd & $\mathrm{Cmp}$ & Sub & Svn & $\mathrm{Cbc}$ & Osr & \\
\hline \multicolumn{15}{|l|}{ RUBIACEAE } \\
\hline Alibertia concolor (Cham.) K. Schum. & $\mathrm{SB}$ & $\mathrm{C}$ & $\mathrm{x}$ & $\mathrm{x}$ & $\mathrm{x}$ & $\mathrm{x}$ & $\mathrm{x}$ & $\mathrm{x}$ & - & - & - & - & - & - \\
\hline Faramea nigrescens Mart. & $\mathrm{SB}$ & $\mathrm{D}$ & $\mathrm{x}$ & - & - & $\mathrm{x}$ & $\mathrm{x}$ & - & - & - & - & - & - & - \\
\hline Posoqueria latifolia (Rudge) Roem. \& Schult. & DS & A & $\mathrm{x}$ & - & - & $\mathrm{x}$ & - & $\mathrm{x}$ & $\mathrm{x}$ & $\mathrm{x}$ & $\mathrm{x}$ & $\mathrm{x}$ & $\mathrm{x}$ & $\mathrm{x}$ \\
\hline Psychotria leiocarpa Cham. \& Schltdl. & $\mathrm{SB}$ & $\mathrm{E}$ & - & $\mathrm{x}$ & - & $\mathrm{x}$ & - & - & $\mathrm{x}$ & - & - & - & - & $\mathrm{x}$ \\
\hline \multicolumn{15}{|l|}{ RUTACEAE } \\
\hline Dictyoloma vandellianum A.H.L. Juss. & DS & $\mathrm{B}$ & - & - & - & - & $\mathrm{x}$ & - & - & - & - & - & $\mathrm{x}$ & - \\
\hline \multicolumn{15}{|l|}{ SALICACEAE } \\
\hline Casearia decandra Jacq. & DS & A & $\mathrm{x}$ & - & - & $\mathrm{x}$ & - & - & - & - & - & - & - & - \\
\hline \multicolumn{15}{|l|}{ SAPINDACEAE } \\
\hline Cupania ludowigii Somner \& Ferrucci & DS & $\mathrm{E}$ & - & $\mathrm{x}$ & - & $\mathrm{x}$ & - & $\mathrm{x}$ & - & - & - & - & - & - \\
\hline Matayba guianensis Aubl. & DS & A & $\mathrm{x}$ & $\mathrm{x}$ & - & $\mathrm{x}$ & - & $\mathrm{x}$ & $\mathrm{x}$ & $\mathrm{x}$ & $\mathrm{x}$ & $\mathrm{x}$ & $\mathrm{x}$ & $\mathrm{x}$ \\
\hline \multicolumn{15}{|l|}{ SAPOTACEAE } \\
\hline Pouteria andarahiensis T.D. Penn. & SB & $\mathrm{D}$ & - & - & - & - & - & $\mathrm{x}$ & - & - & - & - & - & - \\
\hline Pouteria reticulata (Engl.) Eyma & DS & A & - & $\mathrm{x}$ & - & - & $\mathrm{x}$ & $\mathrm{x}$ & $\mathrm{x}$ & $\mathrm{x}$ & $\mathrm{x}$ & $\mathrm{x}$ & $\mathrm{x}$ & - \\
\hline Pouteria torta (Mart.) Radlk. & EM & A & - & - & - & - & - & - & $\mathrm{x}$ & $\mathrm{x}$ & $\mathrm{x}$ & $\mathrm{x}$ & $\mathrm{x}$ & $\mathrm{x}$ \\
\hline \multicolumn{15}{|l|}{ SIMAROUBACEAE } \\
\hline Simarouba amara Aubl. & DS & A & $\mathrm{x}$ & $\mathrm{x}$ & - & - & - & - & $\mathrm{x}$ & - & $\mathrm{x}$ & $\mathrm{x}$ & $\mathrm{x}$ & - \\
\hline \multicolumn{15}{|l|}{ SOLANACEAE } \\
\hline Aureliana brasiliana (Hunz.) Barboza \& Hunz. & SB & $\mathrm{E}$ & $\mathrm{x}$ & - & - & - & - & - & - & - & - & - & - & - \\
\hline Brunfelsia uniflora (Pohl) D. Don & $\mathrm{SB}$ & $\mathrm{B}$ & - & - & - & - & - & - & $\mathrm{x}$ & - & - & - & - & $\mathrm{x}$ \\
\hline Solanum cladotrichum Vand. ex Dunal & $\mathrm{SB}$ & $\mathrm{D}$ & - & - & - & - & - & - & - & - & $\mathrm{x}$ & - & - & - \\
\hline \multicolumn{15}{|l|}{ SYMPLOCACEAE } \\
\hline Symplocos lanceolata (Mart.) A. DC. & SB & $\mathrm{E}$ & - & - & - & - & $\mathrm{x}$ & - & - & - & - & - & - & - \\
\hline Symplocos nitens (Pohl.) Benth. & SD & $\mathrm{C}$ & $\mathrm{x}$ & - & - & - & - & $\mathrm{x}$ & $\mathrm{x}$ & $\mathrm{x}$ & $\mathrm{x}$ & $\mathrm{x}$ & $\mathrm{x}$ & $\mathrm{x}$ \\
\hline \multicolumn{15}{|l|}{ THEACEAE } \\
\hline Gordonia fruticosa (Schrad.) H. Keng & DS & A & - & - & - & - & - & - & $\mathrm{x}$ & $\mathrm{x}$ & $\mathrm{x}$ & - & $\mathrm{x}$ & - \\
\hline Ternstroemia alnifolia Wawra. & SB & $\mathrm{D}$ & $\mathrm{x}$ & - & $\mathrm{x}$ & - & - & - & $\mathrm{x}$ & - & - & - & - & - \\
\hline \multicolumn{15}{|l|}{ THYMELAECEAE } \\
\hline Daphnopsis utilis Warm. & SB & $\mathrm{E}$ & - & - & - & - & - & - & - & - & $\mathrm{x}$ & - & $\mathrm{x}$ & $\mathrm{x}$ \\
\hline \multicolumn{15}{|l|}{ VOCHYSIACEAE } \\
\hline Qualea cryptantha (Spreng.) Warm. & SB & A & - & - & - & - & - & $\mathrm{x}$ & - & - & - & - & - & - \\
\hline Vochysia acuminata Bong. & DS & $\mathrm{E}$ & - & - & - & $\mathrm{x}$ & - & - & - & - & - & - & - & $\mathrm{x}$ \\
\hline Vochysia oppugnata (Vell.) Warm. & EM & $\mathrm{E}$ & $\mathrm{x}$ & - & - & - & - & $\mathrm{x}$ & $\mathrm{x}$ & $\mathrm{x}$ & $\mathrm{x}$ & $\mathrm{x}$ & $\mathrm{x}$ & $\mathrm{x}$ \\
\hline Vochysia tucanorum Mart. & DS & SD & $\mathrm{x}$ & $\mathrm{x}$ & $\mathrm{x}$ & $\mathrm{x}$ & $\mathrm{x}$ & - & - & - & - & - & - & - \\
\hline \multicolumn{15}{|l|}{ WINTERACEAE } \\
\hline Drimys brasiliensis Miers & $\mathrm{SD}$ & $\mathrm{B}$ & - & - & - & - & - & - & $\mathrm{x}$ & $\mathrm{x}$ & - & $\mathrm{x}$ & - & $\mathrm{x}$ \\
\hline
\end{tabular}

atingem também o centro-oeste. Algumas dessas espécies, como Euterpe edulis e Ocotea daphnifolia, ocorrem na floresta Atlântica do nordeste e do sudeste. Outras, como Ocotea glaziovii, Aureliana brasiliana e Daphnopsis utilis, ocorrem apenas na floresta Atlântica do sudeste e Ficus bahiensis ocorre só na floresta Atlântica do nordeste. Ou- tras espécies, como Eremanthus glomerulatus e Ocotea pomaderroides, ocorrem nas matas da cadeia do Espinhaço (MG e BA) e no Brasil central. As restantes 13 espécies são exclusivas da floresta Atlântica. Poucas espécies ocupam áreas do nordeste e do sudeste, sendo a maioria restrita à floresta Atlântica do sudeste, como Persea major, Inga 
lenticellata, Myrceugenia alpigena, Podocarpus lambertii e Cupania ludowigii, ou do nordeste, como Miconia caudigera e Myrcia blanchetiana.

Trinta e oito espécies $(32,5 \%)$ podem ser encontradas em todos os estados da região sudeste, trinta e uma $(26,5 \%)$ nos estados do Distrito Federal e Goiás, e vinte e uma (18 $\%)$ nos estados da região sul. Somente duas espécies $(1,7$ $\%)$, Eugenia punicifolia e Myrcia guianensis, podem ser encontradas em todos os estados da região nordeste.

Duas espécies são, até o momento, endêmicas destas florestas alto-montanas: Ocotea sp. nov. ined. e Schefflera sp. nov. ined. Indivíduos pertencentes a Ocotea sp. são raros na Serra das Almas. Foram encontrados apenas no fragmento GAI. Já, indivíduos pertencentes a Schefflera sp., são raros nos fragmentos da Serra da Mesa, tendo sido encontrados apenas no fragmento SUB, e não foram encontrados na Mata do Cigano e nos fragmentos da Serra das Almas.

\section{Discussão}

As florestas alto-montanas encontradas na porção sul da Chapada Diamantina são peculiares, pois são as únicas formações florestais da região nordeste situadas acima dos 1300 m.s.n.m. Embora tenha havido um grande esforço de coleta (Stannard 1995; Zappi et al.2003), existem poucos registros e inexistem levantamentos sistemáticos das formações florestais na região. A comparação das espécies, inventariadas neste trabalho com outros levantamentos florísticos, mostra que 17 não foram referidas entre as 8.294 espécies de angiospermas constantes na listagem das plantas do nordeste brasileiro (Barbosa et al. 2006). Outras 37 estão ausentes da lista das plantas vasculares de Catolés, Chapada Diamantina, levantamento realizado na região de uma das áreas de estudo (Mata do Cigano), para onde foram anotadas 1.713 espécies (Zappi et al. 2003). O mesmo se dá em relação às coletas realizadas no Pico das Almas e adjacências, 55 espécies encontradas no presente trabalho não foram referidas na flora do Pico das Almas, onde foram listadas cerca de 1.200 espécies (Stannard 1995). A partir de presente levantamento obteve-se a primeira citação de Rhamnus sphaerosperma para o Estado da Bahia e a segunda ocorrência de Vochysia oppugnata, também para a Bahia, desde a década de 1970 (Vianna 1980).

A composição florística da área de estudo também chama a atenção devido ao baixo compartilhamento de espécies com outras florestas montanas da Chapada Diamantina. Souza (2007), estudando a composição florística e a estrutura de uma mata de encosta no Parque Nacional da Chapada Diamantina (PNCD, Palmeiras, BA), encontrou 97 espécies, das quais apenas nove são comuns à área estudada, sendo que quatro destas são consideradas de distribuição neotropical: Alchornea triplinervia, Guapira opposita, Posoqueria latifolia e Pouteria torta. Estudos realizados por Couto (2006) mostram que é também baixo o número de espécies compartilhadas entre as florestas estacionais sub-montanas, que se desenvolvem no PNCD, e as forma- ções alto-montanas. Das 88 espécies arbóreas listadas pela autora, onze são comuns a área de estudo, sendo que seis delas são amplamente distribuídas nos neotrópicos, entre as quais Aspidosperma discolor e Casearia decandra; três apresentam distribuição disjunta entre o norte da América do Sul e leste do Brasil, como Myrsine umbellata; Heisteria perianthomega apresenta padrão de distribuição entre o leste e o centro-oeste brasileiro e Symplocos nitens possui distribuição peri-amazônica.

Estudos realizados por Funch (2008) e Funch et al. (2008), na Serra do Sincorá (PNCD), listaram 139 espécies, das quais 31 são comuns à flora das florestas alto-montanas. Daquelas, quatorze apresentam distribuição neotropical (Handroanthus ochraceus e Ocotea aciphylla, p. e.), dez apresentam distribuição disjunta entre o norte da América do Sul e leste do Brasil, podendo ser citadas Guatteria sellowiana e Drimys brasiliensis; Alibertia concolor apresenta distribuição peri-amazônica; Eremanthus incanus, Ocotea percoriacea e Ternstroemia alnifolia apresentam distribuição restrita à cadeia do Espinhaço e três apresentam distribuição entre o leste e o centro-oeste brasileiro, entre as quais Miconia chartacea.

Apesar das florestas alto-montanas estarem inseridas dentro da região semi-árida, estas guardam pouca relação com a flora estacional comumente encontrada no entorno da Chapada Diamantina. Isto pode ser evidenciado pelos estudos de Oliveira-Filho et al. (2006), enfocando as florestas estacionais semideciduais e deciduais orientais da América do Sul. De uma lista de 3018 espécies pertencentes àquelas florestas, são encontradas apenas 34 espécies comuns à área de estudo, sendo que a maioria destas é referida pelos autores como supertramp, entre as quais vale a pena citar: Cabralea canjerana, Eugenia punicifolia e Myrcia guianensis.

Estudos florísticos realizados na Floresta Atlântica montana do sul da Bahia, mais próxima ao litoral, registraram um total de 1.129 espécies de angiospermas, das quais cerca de 530 possuíam hábito arbóreo (Amorim et al. 2009). Destas, 27 espécies foram comuns às florestas altomontanas nordestinas. Hedyosmum brasiliense, Lamanonia ternata, Alchornea triplinervia, Ormosia fastigiata, Ocotea aciphylla, Ficus citrifolia, Piper cernuum, Casearia decandra, Matayba guianensis, Simarouba amara e Laplacea fruticosa possuem distribuição neotropical. Clethra scabra, Weinmannia paullinifolia, Cabralea canjerana, Myrsine umbellata, Calyptranthes pulchella, Guapira opposita, Hyeronima alchorneoides e Drimys brasiliensis possuem padrão de distribuição disjunto entre o norte da América do Sul e o leste do Brasil. Blepharocalyx salicifolius possui distribuição peri-amazônica e Annona cacans, Euterpe edulis, Ocotea daphnifolia, Leandra melastomoides, Miconia chartacea, Tibouchina fissinervia e Eugenia rostrata possuem padrão de distribuição disjunto entre o leste e o centro-oeste do Brasil. No entanto, a alta diversidade encontrada na floresta Atlântica montana do sul da Bahia contrasta com as florestas da área de estudo. Enquanto que 
27 espécies representam cerca de $23 \%$ das encontradas nas florestas alto-montanas, o mesmo número representa apenas $5 \%$ das espécies encontradas nas florestas montanas baianas próximas ao litoral. Possivelmente, tal fato ocorra devido às diferenças entre esses ambientes, tendo fatores como distância do oceano (cerca de $300 \mathrm{~km}$ para as florestas alto-montanas da Chapada Diamantina), pluviosidade, sazonalidade, amplitude térmica, profundidade e fertilidade do solo, entre os principais determinantes.

Oliveira-Filho \& Fontes (2000), estudando padrões florísticos e suas diferenciações na floresta Atlântica do sudeste brasileiro, geraram uma lista de 125 áreas de floresta Atlântica e 1002 espécies. Destas, apenas 29 são encontradas na área de estudo, das quais onze são comuns às florestas montanas ombrófilas e semidecíduas da Mata Atlântica do sudeste, entre elas: Drimys brasiliensis, Weinmania pauiliniifolia e Hedyosmum brasiliense. D. Brasiliensis e W. pauiliniifolia são também encontradas nas florestas montanas disjuntas entre o norte da América do Sul e o leste do Brasil; já $H$. brasiliense, é encontrada em florestas montanas da América do Sul. Outras nove espécies encontradas nas florestas estudadas são novamente referidas como supertramp, podendo ser citadas: Casearia decandra, Guapira opposita e Myrsine umbellata.

Excetuando-se as florestas das formações montanas da Chapada Diamantina (Funch 2008; Funch et al. 2008), a área que, proporcionalmente, mais compartilhou espécies com a área de estudo foi uma floresta alto-montana da serra da Mantiqueira, no município de Camanducaia, Minas Gerais (França \& Stehmann 2004). Das 66 espécies encontradas pelos autores, treze $(20 \%)$ são comuns às florestas alto-montanas da Chapada Diamantina, podendo ser citada Myrceugenia alpigena, que se distribui pela floresta Atlântica do sul e sudeste, serra da Mantiqueira e cadeia do Espinhaço. O compartilhamento de espécies entre a área de estudo e a flora arbórea da serra da Mantiqueira também é evidenciado pelos estudos realizados em remanescentes florestais do maciço do Itatiaia, nas divisas dos estados de Minas Gerais e Rio de Janeiro (Pereira et al. 2006). Existem 38 espécies comuns entre as duas localidades, entre as quais se pode destacar Euplassa legalis, que possui distribuição fragmentada entre a floresta Atlântica montana do sul/sudeste e a cadeia do Espinhaço, e Cupania ludowigii, que se distribui de forma disjunta entre a floresta Atlântica montana do sudeste e do estado de Pernambuco e a cadeia do Espinhaço. Deve-se ressaltar que estas florestas estão a cerca de 1.150 (França \& Stehmann 2004) e 1.000 km (Pereira et al. 2006) de distância da área de estudo.

No entanto, os dados gerados pelos estudos realizados por Oliveira-Filho et al. (2005) por meio da análise florística do compartimento arbóreo de áreas de floresta Atlântica sensu lato na região das bacias do leste (BA, MG, ES e $\mathrm{RJ})$, que incluem grandes maciços florestais e de agrofloresta, apontam o maior número de espécies comuns à área de estudo (60; cerca de 52\%), podendo ser citadas Sloanea monosperma, emergente na Mata do Cigano, que possui distribuição neotropical, Podocarpus lambertii e Euterpe edulis, que apresentam padrão de distribuição restrito ao leste e centro-oeste brasileiros, sendo os indivíduos de $P$. lambertii comumente encontrados em formações montanas e associados a temperaturas amenas (França \& Stehmann 2004; Pereira et al. 2006), enquanto que E. edulis é considerado indicador de áreas úmidas na floresta Atlântica (Amorim et al. 2005).

A maioria das espécies encontradas apresenta ampla distribuição geográfica, sendo também este o padrão de distribuição encontrado por Funch (1997) e Funch et al . (2008). Os autores propõem que a flora da Chapada Diamantina, como um todo, seria o resultado do afluxo de diferentes floras (p.e. Caatinga, Carrasco e florestas Atlântica, Amazônica, do Brasil Central e Andina), enfatizando o proposto por Harley \& Simmons (1986) de que as florestas da Chapada Diamantina são compostas por espécies de distribuição ampla e também por aquelas de distribuição restrita. Mori \& Boom (1981), analisando padrões de distribuição de 127 espécies arbóreas na Mata Atlântica do sul da Bahia, mostraram que $26 \%$ das espécies encontradas possuíam ampla distribuição geográfica. Ocorrência confirmada por Giulietti \& Pirani (1988) em estudos realizados com a flora da cadeia do Espinhaço, em Minas Gerais. Somam-se às precedentes grande número de espécies endêmicas (e. g. Stannard 1995; Zappi et al. 2003).

Ocorrem também na área de estudo espécies de distribuição mais restrita, como Vochysia oppugnata, que é referida para a floresta Atlântica montana do Rio de Janeiro, disjunções da serra do Espinhaço, em Minas Gerais, e para a floresta Atlântica montana próxima ao litoral da Bahia (Vianna 1980). Miconia caudigera é encontrada na floresta Atlântica litorânea dos estados da Bahia e Alagoas. Ilex psammophila ocorre na floresta Atlântica litorânea da Bahia e na serra da Mantiqueira, no estado de Minas Gerais. O padrão de distribuição apresentado por estas espécies sugere uma ligação pretérita entre a floresta Atlântica montana e de terras baixas (do sul, sudeste e nordeste), com as formações montanhosas encontradas na serra da Mantiqueira e as porções alto-montanas da Chapada Diamantina.

Segundo Harley \& Simmons (1986), as formações montanas da Chapada Diamantina poderiam ser comunidades relictuais de um período quando a cobertura florestal da região nordeste era maior e, possivelmente, havia uma ligação florestal entre a floresta Atlântica e a bacia Amazônica. Algumas das espécies amostradas nas florestas alto-montanas da Chapada Diamantina sugerem estas ligações pretéritas, sobretudo entre a floresta Atlântica e as regiões ao norte da bacia Amazônica, entre elas Baccharis brachylaenoides, que apresenta distribuição disjunta entre a floresta Atlântica montana do sul e sudeste, o Brasil central, as formações andinas e o planalto das Guianas; Clusia melchiori possui distribuição disjunta entre a Mata Atlântica montana e de terras baixas da Bahia 
e o planalto das Guianas, e Eugenia ligustrina possui distribuição fragmentada entre a área de estudo, a floresta estacional semidecidual do estado de São Paulo, planalto das Guianas e Porto Rico, no mar do Caribe. Espécies como Weinmannia paulliniifolia, Drimys brasiliensis e Clethra scabra, comumente encontradas em altitudes elevadas nos neotrópicos, são incluídas em gêneros com centros de diversidade nos Andes (Giulietti \& Pirani 1988; Harley 1995). Maguire (1970) considera que os escudos Guiano e Brasileiro eram muito mais próximos antes do Mioceno e da formação dos Andes. Para Harley (1995), estes gêneros apareceram antes do Eoceno e podem ser representantes da flora autóctone que ocorria na América do Sul até o Oligoceno, mas que se tornaram atualmente restritos às montanhas das duas regiões.

Chama atenção a importância das famílias Myrtaceae, Lauraceae, Melastomataceae, Asteraceae, e Rubiaceae na composição da flora das florestas alto-montanas da Chapada Diamantina. Com exceção de Asteraceae, estas famílias são comumente apontadas dentre as mais ricas em espécies lenhosas no mundo (Takhtajan 1997; Cronquist 1981; Yamamoto et al. 2005). Possuem alta riqueza tanto em formações montanas quanto submontanas na floresta estacional semidecidual (Leitão-Filho 1982; Santos \& Kinoshita 2003; Yamamoto et al. 2005) e na floresta Atlântica montana (Mori et al. 1983; Tabarelli \& Mantovani 1999). Segundo Gentry (1982; 1988; 1990), estas seriam as famílias com maior riqueza de espécies nas florestas neotropicais montanas. As principais famílias em número de espécies, encontradas na área de estudo, estão entre as dez mais importantes na composição da floresta Atlântica montana e baixo-montana do sudeste brasileiro (Oliveira-Filho \& Fontes 2000) e da floresta Atlântica de terras baixas em Santa Catarina (Negrelle 2002). O mesmo se dá em relação aos gêneros encontrados com maior número de espécies. Segundo dados dos mesmos autores, Ocotea, Eugenia, Myrcia e Miconia, estão entre os cinco gêneros mais importantes na flora das florestas alto e baixo-montanas do sudeste (Oliveira-Filho \& Fontes 2000) e entre os sete mais importantes gêneros na composição da floresta Atlântica de terras baixas, em Santa Catarina (Negrelle 2002). Estes estudos e os precedentes sugerem uma forte influência da flora da floresta Atlântica do sul, sudeste e da Bahia, principalmente em sua porção oriental, sobre a flora das florestas alto-montanas encontradas na porção sul da Chapada Diamantina.

Tomando-se as porções montanhosas da Chapada Diamantina como um todo, observa-se que, entre as cotas altitudinais de 400 a 1100 m.s.n.m., nota-se, nas formações florestais, a presença de famílias comumente associadas a climas mais quentes e formações de terras baixas encontradas na região neotropical. Funch et al. (2008), em estudos realizados nas formações montanas e baixo-montanas da porção central da Chapada Diamantina, encontraram famílias como Chrysobalanaceae, Combretaceae, Ebenaceae, Erythroxylaceae, Icacinaceae, Lacistemaceae, Lecythida- ceae e Loganiaceae. Estas, com exceção de Loganiaceae (representada apenas pela espécie arbórea Antonia ovata, com distribuição neotropical), são famílias cuja maior diversificação ocorre em áreas mais quentes, tendo Chrysobalanaceae e Lecythidaceae centro de diversidade na Amazônia (Prance 1987). Representantes destas famílias não foram encontradas nas formações florestais da área de estudo. Por outro lado, as famílias Cunnoniaceae, Oleaceae, Phyllanthaceae, Rhamnaceae, Rosaceae, Symplocaceae e Thymelaeaceae, encontradas na área de estudo, só ocorrem nas florestas em altitudes maiores que 1.500 m.s.n.m. Oleaceae e Rosaceae são famílias essencialmente de climas temperados, com poucas espécies no Brasil. Cunnoniaceae ocorre principalmente nas florestas de altitude da floresta Atlântica do sudeste (França \& Stehmann 2004; Pereira et al. 2006) e sul (Negrelle 2002). Rhamnaceae tem o gênero Rhamnus, com distribuição especialmente temperada, com uma só espécie no Brasil (Lima \& Giulietti 2005), enquanto Symplocus (Symplocaceae) e Daphnopsis (Thymelaeaceae) têm distribuição neotropical a subtropical, com suas espécies concentradas mais nas regiões sudeste e sul do Brasil.

Para Funch et al. (2008), as famílias com maiores número de espécies são: Myrtaceae, Leguminosae, Melastomataceae, Euphorbiaceae e Clusiaceae, sendo registradas apenas três espécies de Lauraceae. Nas florestas alto-montanas da Chapada Diamantina, as famílias com maiores números de espécies são Myrtaceae, Lauraceae, Melastomataceae e Asteraceae. Há uma diminuição na riqueza de famílias como Leguminosae e Clusiaceae. Deve ser destacado que Myrtaceae é a família mais rica em espécies nos dois tipos de florestas, porém, Leguminosae é gradativamente substituída pelas Lauraceae à medida que são atingidas maiores altitudes. Gentry (1995) constatou que há perda na riqueza de Leguminosae e aumento na importância de Lauraceae a partir dos 1.500 m.s.n.m., nas florestas andinas e da América Central.

Prance et al. (2000) sugerem que grande parte da flora neotropical e mundial ainda não foi amostrada ou descrita. No Brasil, após cerca de 500 anos de transformação, restam apenas cerca de 7 \% da Mata Atlântica, que outrora se estendia do Rio Grande do Norte ao Rio Grande do Sul (Fundação SOS Mata Atlântica \& INPE 2009). Mori \&Boom (1981) mostraram que, das 127 espécies de árvores descritas nas monografias da Flora Neotrópica, 53,5\% eram endêmicas da Mata Atlântica e, com base na velocidade de conversão da Mata Atlântica em paisagens antropizadas, aventaram a possibilidade de algumas destas espécies já estarem extintas. No presente estudo, quatro espécies foram coletadas apenas na Mata do Cigano, oito nos fragmentos da Serra da Mesa e trinta e sete nos fragmentos da Serra das Almas. Estudos de inventários nas florestas neotropicais sugerem que grande parte das espécies arbóreas ocorre em baixa freqüência e haveria ainda a existência de grande proporção de espécies exclusivas (Hubbell \& Foster 1983; Scudeller 2001; Turner 2001; Neves 2005; Grillo et al. 2006; Martini et al. 2007; Macedo 2007). Com base nestas proposições, Myers (1988) 
concluiu que a grande extinção em massa de espécies na floresta Atlântica já aconteceu.

No entanto, afirmações sobre extinção ou não extinção de espécies devem ser também tomadas com extrema cautela. A maior parte da floresta Atlântica convertida em ambientes antrópicos era de áreas planas ou pouco acidentadas, ou seja, ambientes com menor heterogeneidade ambiental, quando comparados com as áreas da floresta Atlântica montana. Durante a realização do presente trabalho, foi observado, através de imagens de satélite (Google Earth), que a maior parte da floresta Atlântica remanescente no Brasil encontra-se em áreas montanhosas, ou seja, locais que, por suas características físicas, comportariam maior número de espécies, já que seriam áreas com maior heterogeneidade ambiental. Deste modo, a grande perda que ocorreu no bioma pode ter sido em extensão e em número de indivíduos, mas talvez não na mesma proporção em número de espécies. É possível que a maior parte das espécies que compunham a floresta Atlântica de terras baixas ainda esteja preservada nas porções restantes da floresta. Tal hipótese não visa minimizar a importância da floresta que foi transformada, pelo contrário, pois se perdeu muito na manutenção dos serviços ambientais que elas proporcionavam, como por exemplo, a manutenção da qualidade da água e a contenção dos processos erosivos, fatos estes que por si só já diminuem em muito a qualidade da vida humana. Portanto, é imprescindível e imediato que sejam postas em prática formas de preservação. Uma premissa importante para o sucesso da preservação do que restou da floresta Atlântica é a participação de todas as camadas da sociedade nas discussões, atendendo inicialmente a projetos de recuperação de bacias de drenagem e criação de corredores ecológicos.

\section{Agradecimentos}

Os autores agradecem a todos os especialistas que identificaram o material botânico, ao Programa de Pós-Graduação em Botânica da Universidade Estadual de Feira de Santana, pela infra-estrutura oferecida, aos habitantes dos municípios de Rio de Contas e Rio do Pires, que, direta e indiretamente, auxiliaram no trabalho de campo, ao Conselho Nacional de Desenvolvimento Científico e Tecnológico (CNPq), pela bolsa de doutorado para o primeiro autor (processo $\mathrm{n}^{\circ} 141600 / 2005-5$ ) e bolsas de produtividade para os dois outros autores, e à Fundação de Amparo à Pesquisa do Estado da Bahia (FAPESB) pelo apoio ao projeto de doutorado (termo de outorga $\mathrm{n}^{\circ}$ APR0205/2005).

\section{Referências Bibliográficas}

Amorim, A.M.; Fiaschi, P.; Jardim, J.G.; Thomas, W.W.; Clifton, B.C. \& Carvalho, A.M.V. 2005. The vascular plants of a forest fragment in Southern Bahia, Brazil. Sida 21: 1727-1752.

Amorim, A.M.; Jardim, J.G.; Lopes, M.M.M.; Fiaschi, P.; Borges, R.A.X.; Perdiz, R.O. \& Thomas, W.W. 2009. Angiospermas em remanescentes de Floresta Montana no sul da Bahia, Brasil. Biota Neotropica 9(3): http://www.biotaneotropica.org.br/v9n3/en/abstract?inventory+ bn02909032009.

Andrade, G.O. 1954. A Serra Negra - uma relíquia geomorfológica e higrófita nos tabuleiros pernambucanos. Recife, Imprensa Oficial.
Andrade-Lima, D. 1953. Notas sobre a dispersão de algumas espécies vegetais no Brasil. Anais da Sociedade de Biologia de Pernambuco 11: 25-49.

Angiosperm Phylogeny Group. 2003. An update of the Angiosperm Phylogeny Group classification of the orders and families of flowering plants: APG II. Botanical Journal of Linnean Society 141: 399-436.

Baldwin, B.G. 2006. Contrasting patterns and processes of evolutionary change in the tarweed-silversword lineage: revisiting Clausen, Keck, and Hiesey's findings. Annals of the Missouri Botanical Garden 93: 64-93.

Barbosa, M.R.; Sothers, C.; Mayo, S.; Gamarra-Rojas, C.F.L. \& Mesquita, A.C. (orgs.). 2006. Checklist das plantas do Nordeste Brasileiro: Angiospermas e Gimnospermas. Brasília, Ministério de Ciência e Tecnologia.

Couto, A.P.L. 2006. Composição florística e estrutura de uma floresta estacional submontana, Parque Nacional da Chapada Diamantina, Lençóis, Bahia, Brasil. Dissertação (Mestrado, Botânica), Feira de Santana. Universidade Estadual de Feira de Santana.

Cronquist, A. 1981. An integrated system of classification of flowering plants. New York, Columbia University Press.

França, G.S \& Stehmann, J.R. 2004.Composição florística e estrutura do componente arbóreo de uma floresta altimontana no município de Camanducaia, Minas Gerais, Brasil. Revista Brasileira de Botânica 27(1): 19-30.

Funch, L.S. 1997. Composição florística e fenologia de mata ciliar e mata de encosta adjacentes ao Rio Lençóis, Lençóis, BA. Tese. (Doutorado, Botânica), Campinas. Universidade de Campinas.

Funch, L.S.; Funch, R.R.; Harley, R.; Giulietti, A.M.; Queiroz, L.P.; França, F.; Melo, E.; Gonçalves, C.N.; Santos, T. 2005. Florestas Estacionais semideciduais. Pp. 191-193. In: Juncá, F.A.; Funch, L.S. \& Rocha, W. (eds). Biodiversidade e Conservação da Chapada Diamantina. Brasília, Ministério do Meio Ambiente.

Funch, L.S. 2008. Florestas da região Norte do Parque Nacional da Chapada Diamantina e seu entorno. Pp. 63-77. In: Funch, L.S.; Funch, R.R. \& Queiroz, L.P. (orgs.). Serra do Sincorá: Parque Nacional da Chapada Diamantina. Feira de Santana, Radami Editora Gráfica.

Funch, L.S.; Rodal, M.J.N. \& Funch, R.R. 2008. Floristic aspects of forests of the Chapada Diamantina, Bahia, Brazil. Pp. 193-221. In: Wayt Thomas, Wm. (ed.). The Atlantic coastal forest of northeastern Brazil. New York, The New York Botanical Garden Press.

Fundação SOS Mata Atlântica \& INPE (Instituto Nacional de Pesquisas Espaciais). 2009. Atlas dos remanescentes florestais da Mata Atlântica, período de 2005-2008. São Paulo, Fundação SOS Mata Atlântica \& São Jose dos Campos, INPE.

Gentry, A.H. 1982. Patterns of neotropical plant species diversity. Evolutionary Biology 15:1-84.

Gentry, A.H. 1988. Changes in plant community diversity and floristic composition on environmental and geographical gradients. Annals of the Missouri Botanic Garden 75: 1-34.

Gentry, A.H. 1990. Four neotropical rain forests. London, Yale University Press.

Gentry, A.H. 1995. Patterns of diversity and floristic composition in neotropical montane forests. Pp. 103-126. In: Churchill, S.P.; Balslev, H; Forero, E. \& Luteyn, J.L. (eds.). Biodiversity and conservation of neotropical montane forests. New York, The New York Botanical Garden Press.

Giulietti, A.M. \& Pirani, J.R. 1988. Patterns of geographic distribution of some plant species from the Espinhaço range, Minas Gerais and Bahia, Brazil. Pp. 311-318. In: Heyer, R. \& P.E. Vanzolini (eds.) Proceedings of the workshop on neotropical distribution patterns. Rio de Janeiro, Academia Brasileira de Ciências.

Giulietti, A.M.; Queiroz, L.P. \& Harley, R.M. 1996. Vegetação e Flora da Chapada Diamantina, Bahia. Pp. 144-156. Anais da $4^{\text {a }}$ Reunião Especial da SBPC. Feira de Santana.

Grillo, A.; Oliveira, A.A. \& Tabarelli, M. 2006. Árvores. Pp. 190-216. In: Pôrto, K.C.; Almeida-Cortez, J.S. \& Tabarelli, M. (orgs.). Diversidade biológica e conservação da Floresta Atlântica ao Norte do Rio São Francisco. Bodiversidade 14. Brasília, Ministério do Meio Ambiente.

Harley, R.M. 1995. Introduction. Pp. 1-40. In: Stannard, B.L. (ed.). Flora of the Pico das Almas, Chapada Diamantina, Bahia, Brazil. Kew, Royal Botanic Gardens. 
Harley, R.M. \& Simmons, N.A. 1986. Florula of Mucugê, Chapada Diamantina, Bahia, Brazil. Kew, Royal Botanic Gardens.

Hubbell, S.P. \& Foster, R.B. 1983. Diversity of canopy trees in a Neotropical forest and implications for conservation. Pp. 25-41. In: Sutton, S.L.; Whitmore, T.C. \& Chadwick, A.C. (eds.). Tropical rain forest: ecology and management. Oxford, Blackwell.

Laurance, W.F.; Cochrane, M.A.; Bergen, S.; Fearnside, P.M.; Delamônica, P.; Barber, C.; D'Angelo, S. \& Fernandes, T. 2001. Rhe future of the Brazilian Amazon. Science 291: 438.

Leitão-Filho, H.F. 1982. Aspectos taxonômicos das florestas do estado de São Paulo. Silvicultura em São Paulo 16A: 197-206.

Lima, R.B. \& Giulietti, A.M. 2005. Rhamnaceae. Pp. 331-341. In: Flora Fanerogâmica do Estado de São Paulo, vol. 4. São Paulo, FAPESP/ Huncitec.

Köppen, W. 1936. Das geographische system der klimatologie. Berlim, Borntrager.

Macedo, G.E.L. 2007. Composição florística e estrutura do componente arbóreo-lianescente de um trecho de floresta estacional semidecidual no município de Jequié, Bahia, Brasil. Tese. (Doutorado, Botânica). Recife, Universidade Federal Rural de Pernambuco.

Martinelli. G. 2007. Mountain biodiversity in Brazil. Revista Brasileira de Botânica 30: 587-597.

Martini, A.M.Z.; Fiaschi, P.; Amorim, A.M. \& Paixão, J.L. 2007. A hotpoint within a hot-spot: a high diversity site in Brazil's Atlantic Forest. Biodiversity and Conservation 16: 3111-3128.

Maguire, B. 1970. On the flora of Guyana Highland. Biotropica 2:85-100.

Meguro, M.; Pirani, J.R.; Mello-Silva, R. \& Giulietti, A.M. 1996. Estabelecimento de matas ripárias e capões nos ecossistemas campestres da Cadeia do Espinhaço, Minas Gerais. Boletim de Botânica da Universidade de São Paulo 15:1-11.

Mori, S.A. \& Boom, B.M. 1981. Final report to the World Wildlife Found-US on the botanical survey of the endangered moist forests of eastern Brazil. New York, New York Botanical Garden.

Mori, S.A.; Boom, B.M.; Carvalino, A.M. \& Santos, T.S. 1983. Ecological importance of Myrtaceae in an eastern brazilian wet forest. Biotropica 15: $68-70$

Mori, S.A.; Silva, L.A.M.; Lisboa, G. \& Coradin, L. 1989. Manual de manejo de herbário fanerogâmico. Ilhéus, Centro de Pesquisas do Cacau.

Myers, N. 1988. Threatened biotas: "hotspots" in tropical forests. Environmentalist 8: 1-20.

Myers, N.; Mittermeier, R.A.; Mittermeier, C.; Fonseca, G. \& Kent, J. 2000. Biodiversity hotspots for conservation priorities. Nature 403: 853-858.

Negrelle, R.R.B. 2002. The atlantic forest in the Volta Velha Reserve: a tropical rain forest site outside the tropics. Biodiversity and Conservation 11: 887-919.

Neves, M.L.C. 2005. Caracterização da vegetação de um trecho de mata atlântica de encosta na Serra da Jibóia, Bahia. Dissertação. (Mestrado, Botânica), Feira de Santana. Universidade Estadual de Feira de Santana.

Nolasco, C.M.; Lima, C.C.U.; Franca-Rocha, W. \& Rêgo, M.J.M. 2008. Aspectos físicos da Serra do Sincorá, Chapada Diamantina (Bahia). Pp. 17-33. In: Funch, L.S.; Funch, R.R. \& Queiroz, L.P. (eds.). Serra do Sincorá, Parque Nacional da Chapada Diamantina. Feira de Santana, Radami Editora Gráfica.

Oliveira, A. P. \& Andrade-Lima, D. 1948. Serra Negra. Boletim da Secretaria de Agricultura, Indústria e Comércio do Estado de Pernambuco: 388-97.

Oliveira-Filho, A.T. \& Fontes, M.A.L. 2000. Patterns of floristic differentiation among Atlantic Forests in southeastern Brazil and the influence of climate. Biotropica 32: 793-810.
Oliveira-Filho, A.T.; Tameirão-Neto, E.; Carvalho, A.C.; Werneck, M.; Brina, A.E.; Vidal, C.V.; Rezende, S.C. \& Pereira, A.A. 2005. Análise florística do componente arbóreo de áreas de floresta atlântica sensu lato na região das bacias do leste (Bahia, Minas Gerais, Espírito Santo e Rio de Janeiro). Rodriguésia 56: 185-235.

Oliveira-Filho, A.T.; Jarenkow, J.A. \& Rodal, M.J.N. 2006. Floristic relationships of seasonally dry forests of eastern South America based on tree species distribution patterns. Pp. 59-192. In: Pennington, R.T.; Lewis, G.P. \& Ratter, J.A. (eds.). Neotropical savannas and seasonally dry forests: plant diversity, biogeography and conservation. Oxford, Francis CRC Press.

Pereira, I.M.; Oliveira-Filho, A.T.; Botelho, S.A.; Carvalho, W.A.C.; Fontes, M.A.L.; Schiavini, I. \& Silva, A.F. 2006. Composição florística do compartimento arbóreo de cinco remanescentes florestais do maçico do Itatiaia, Minas Gerais e Rio de Janeiro. Rodriguésia 57(1): 103-126.

Prance, G.T. 1987. Biogeography of neotropical plants. Pp. 175-196. In: Whitmore, G.T. \& Prance, G. (eds.). Biogeography and quaternary history in tropical America. Oxford, Claredon Press.

Prance, G.T.; Beentje, H.; Dransfield, J. \& Johns, R. 2000. The tropical flora remains undercollected. Annals of the Missouri Botanical Garden 87:67-71.

Santos, A.M. \& Tabarelli, M. 2002. Distance from roads and cities as a predictor of habitat loss and fragmentation in the Caatinga vegetation of Brazil. Brazilian Journal of Biology 62(4B): 897-905.

Santos, K. \& Kinoshita, L.S. 2003. Flora arbustivo-arbórea de fragmento de floresta estacional semidecidual do Ribeirão Cachoeira, município de Campinas, SP. Acta Botanica Brasilica 17: 325-486.

Scudeller, V.V.; Martins, F.R. \& Shepherd, G.J. 2001. Distribution and abundance of arboreal species in the atlantic ombrophilous dense forest in Southeastern Brazil. Plant Ecology 152: 185-199.

Souza, A.E.A. 2007. Composição florística e estrutura de uma mata de encosta, Serra da Bacia, Parque Nacional da Chapada Diamantina, Palmeiras, Bahia, Brasil. Dissertação, (Mestrado, Botânica). Feira de Santana, Universidade Estadual de Feira de Santana.

Stannard, B.L. 1995. Flora of the Pico das Almas, Chapada Diamantina, Bahia, Brazil. Kew, Royal Botanic Gardens.

Tabarelli, M. \& Mantovani, W. 1999. A riqueza de espécies na floresta atlântica de encosta de São Paulo (Brasil). Revista Brasileira de Botânica 22: 217-223.

Takhtajan, A. 1997. Diversity and classification of flowering plants. New York, Columbia University Press.

Turner, I.M. 2001. The ecology of trees in the tropical rain forest. Cambridge, Cambridge University Press.

Veloso, H.P.; Rangel-Filho, A.L.R. \& Lima, J.C.A. 1991. Classificação da vegetação brasileira adaptada a um sistema universal. Rio de Janeiro, Instituto Brasileiro de Geografia e Estatística.

Vianna, M.C. 1980. O gênero Vochysia Aublet (Vochysiaceae) no Estado do Rio de Janeiro. Rodriguésia 32: 237-326.

Yamamoto, L.F.; Kinoshita, L.S. \& Martins, F.R. 2005. Florística dos componentes arbóreo e arbustivo de um trecho da Floresta Estacional Semidecídua Montana, município de Pedreira, estado de São Paulo. Revista Brasileira de Botânica 28: 191-202.

Zappi, D.C.; Lucas, E.; Stannard, B.L.; Lughadha, E.N.; Pirani, J.R.; Queiroz, L.P.; Atkins, S.; Hind, D.J.N.; Giulietti, A.M.; Harley, R.M. \& Carvalho, A.M. 2003. Lista das plantas vasculares de Catolés, Chapada Diamantina, Bahia, Brasil. Boletim de Botânica da Universidade de São Paulo 21: 345-398. 